\title{
Imaging preictal hemodynamic changes in neocortical epilepsy
}

\author{
Kunal S. Patel, B.A., Mingrui Zhao, Ph.D., Hongtao Ma, Ph.D., \\ ANd Theodore H. Schwartz, M.D.
}

Department of Neurological Surgery, Weill Medical College of Cornell University, New York Presbyterian Hospital, New York, New York

\begin{abstract}
Object. The ability to predict seizure occurrence is extremely important to trigger abortive therapies and to warn patients and their caregivers. Optical imaging of hemodynamic parameters such as blood flow, blood volume, and tissue and hemoglobin oxygenation has already been shown to successfully localize epileptic events with high spatial and temporal resolution. The ability to actually predict seizure occurrence using hemodynamic parameters is less well explored.

Methods. In this article, the authors critically review data from the literature on neocortical epilepsy and optical imaging, and they discuss the preictal hemodynamic changes and their application in neurosurgery.

Results. Recent optical mapping studies have demonstrated preictal hemodynamic changes in both human and animal neocortex.

Conclusions. Optical measurements of blood flow and oxygenation may become increasingly important for predicting and localizing epileptic events. The ability to successfully predict ictal onsets may be useful to trigger closed-loop abortive therapies.

(http://thejns.org/doi/abs/10.3171/2013.1.FOCUS12408)
\end{abstract}

\section{KeY Words • epilepsy $•$ seizure $\quad$ optical imaging • neurosurgery}

$\mathrm{H}$ EMODYNAMIC signals derived from perfusion and oximetry significantly correlate spatially with brain function. They are the fundamental basis of functional neuroimaging. In recent years, there has been great interest in using a variety of brain mapping techniques that measure those hemodynamic responses to assist in clinical diagnosis and management of neurological disorders. In particular, seizures have been shown to elicit a large increase in metabolism, utilization of oxygen, and increases in blood flow and blood volume in epileptic cortex. More recently, it has become apparent that these hemodynamic changes may actually precede seizure onset and be useful at seizure prediction. In the present report, we review the literature on functional optical imaging methods and explore recent data on the timing and the significance of anticipatory preictal hemodynamic changes and their potential application in neurosurgery.

\footnotetext{
Abbreviations used in this paper: $\mathrm{CBF}=$ cerebral blood flow; $\mathrm{CBV}=$ cerebral blood volume $; \mathrm{ECoG}=$ electrocorticography; $\mathrm{EEG}$ = electroencephalography; fMRI = functional MRI; LFP = local field potential; LVFA = low-voltage fast activity; ORIS = optical imaging of intrinsic signals.
}

\section{Prediction of Seizure Onset}

Epilepsy is a clinical term referring to a disease involving recurrent seizures that affects between $1 \%$ and $2 \%$ of the population of the United States. Seizures can be sudden and occur without warning, which can cause significant injuries. The possibility of identifying events, whether they are behavioral, electrographic, or hemodynamic, that reliably occur before epileptic seizures would have a dramatic impact on our ability to warn patients and their families of an upcoming event, thereby giving patients the ability to remove themselves from harm's way. Attempts have been made to forecast epileptic seizures using a variety of methodologies such as EEG, ${ }^{52}$ fMRI, ${ }^{8,12}$ SPECT, ${ }^{42}$ among others. ${ }^{30}$ Such preictal signals could also provide information for "closed-loop" abortive therapies such as cortical stimulation, ${ }^{24}$ focal drug perfusion, ${ }^{11,45}$ cooling, ${ }^{7}$ and optical inhibition. ${ }^{25,49,53}$ Additionally, seizure prediction mechanisms can offer insights into epileptogenesis. ${ }^{16}$

Traditional analysis of EEG signals has not shown any obvious or consistent preictal changes. ${ }^{23,34}$ Complex nonlinear mathematic algorithms for electrographic data can be used to predict seizure with increasing reliabili- 
ty. ${ }^{13,26}$ Recently, our laboratory reported an approximately 20 -sec focal hemodynamic change before seizure onset in human lesional neocortical case. In addition, we have shown preictal vessel constriction as early as $5 \mathrm{sec}$ prior to seizure onset in an animal model using a 2-photon microscope. ${ }^{57,58}$

\section{Intrinsic Optical Mapping of Neurovascular Coupling During Epilepsy}

Neurovascular coupling concerns the relationship among neuronal activity, metabolism, tissue oxygenation, and blood flow. Adequate coupling is critical to supply the energy demands of the brain during normal physiological function as well as pathological conditions. Seizures create a large focal increase in metabolism and result in a dramatic increase in $\mathrm{CBF}$ to the ictal focus to provide adequate oxygenation. Whether $\mathrm{CBF}$ is adequate to meet the demands of an epileptic event has been a longstanding debate.

Optical imaging of intrinsic signals is a technique for measuring hemodynamic changes in the brain and is based on enhanced light absorption of active neural tissue, which is caused by focal increases in $\mathrm{CBF}$, deoxygenation of hemoglobin, and enhanced scattering of light. ${ }^{15,29,33} \mathrm{At}$ wavelengths such as $570 \mathrm{~nm}$, an isosbestic wavelength of hemoglobin, ORIS provides a direct measure of total hemoglobin. Total hemoglobin is equivalent to $\mathrm{CBV}$ if the hematocrit remains constant, and $\mathrm{CBV}$ is proportional to CBF. At $610 \mathrm{~nm}$, deoxygenated hemoglobin absorbs light more strongly than oxygenated hemoglobin, and it is possible to directly quantify both deoxygenated hemoglobin and total hemoglobin with the appropriate calculation. ${ }^{41}$ At $800 \mathrm{~nm}$, or near infrared wavelengths, the optical signal is largely derived from light scattering related to cell swelling as well as intra- and extracellular fluid shifts, which provide an indirect representation of neuronal activity, less influenced by the changes in CBV and hemoglobin oxygenation that dominate the intrinsic signal at lower wavelengths.

Precise localization of neocortical epileptic foci is very important for the neurosurgeon to identify and remove the seizure onset zone to achieve the best surgical outcome. Several studies have shown that ORIS can be used to map the onset and spread of epileptic events via their hemodynamic sequelae with very high spatial and temporal resolution, as well as high spatial sampling. ${ }^{25}$. ${ }^{34-40}$ Epileptic events initiate a large focal increase in metabolism and $\mathrm{CBF}$ at the seizure focus. In contrast, decreases in $\mathrm{CBF}$ have been demonstrated surrounding the focus, the etiology of which is unknown. The relationship between these events and neuronal activity and metabolism is also unknown. Studies using techniques with limited spatial and temporal resolution such as fMRI, PET, SPECT, and autoradiography have shown that the relative increase in CBF more than meets the increase in metabolism leading to an increase in blood oxygenation; however, studies using higher temporal resolution techniques such as near-infrared spectroscopy and ORIS have demonstrated that $\mathrm{CBF}$ is inadequate to meet the metabolic demands of the epileptic tissue, leading to a decrease in both tissue and hemoglobin oxygenation (see review ${ }^{40}$ ).

\section{Optical Signals and Seizure Prediction}

\section{Mapping Preictal Changes in Human Epilepsy}

Optical imaging has been intraoperatively done to map both human epileptic focus and human brain function activity during surgery. ${ }^{3,18,19,35,39,46}$ Beyond localizing human physiological and pathological activity, it was also used to predict the preictal changes in human epilepsy.

The idea of preictal vascular reactivity predicting the seizure onset was proposed (mistakenly at the time) as early as 1933 by Gibbs. ${ }^{17}$ More recently, studies have found increases in cerebral perfusion 20 minutes before focal and generalized spike-and-wave events using transcranial Doppler ultrasonography. ${ }^{10}$ Fortuitously, we recorded ORIS in human cortex intraoperatively in a patient with recurrent focal seizures arising from a cavernous malformation. ${ }^{58}$ We found that focal changes in cerebrovascular hemodynamics preceded the seizure onset by approximately $20 \mathrm{sec}$ and occurred focally over the known location of the lesion and the seizure onsets (Fig. 1). Three spontaneous seizures were successfully recorded, two at $610 \mathrm{~nm}$ and one at $570 \mathrm{~nm}$, providing data on deoxygenated hemoglobin and CBV. Each seizure was accompanied by a dramatic focal change in the intrinsic signal. At $610 \mathrm{~nm}$, a significant increase light reflectance began $23.74 \pm 8.67 \mathrm{sec}$ prior to the electrographic onset of the seizure (Fig. 1D and F). The spatial maps of the two seizures recorded at $610 \mathrm{~nm}$ were remarkably similar. At $570 \mathrm{~nm}$, a significant decrease in light reflectance began $15.0 \mathrm{sec}$ prior to the electrographic onset of the seizure (Fig. 1E), again restricted to the known epileptic gyrus consistent with a focal drop in CBV. Prior to the onset of the seizures, the signal inverted to a significant increase in light reflectance (increase in $\mathrm{CBV}$ ), which reached a maximum amplitude of $46.2 \%$, peaking $58.1 \mathrm{sec}$ after the onset of the seizure. Again the signal was restricted to the known epileptic gyrus consistent with a focal drop in $\mathrm{CBV}$. Prior to the onset of the seizures, the signal inverted to a significant increase in light reflectance (increase in CBV), which reached a maximum amplitude of $46.2 \%$, peaking $58.1 \mathrm{sec}$ after the onset of the seizure. This preictal finding in spontaneous human epilepsy suggests that optical measurements may be useful for predicting the seizure onset and location prior to any electrographic changes.

\section{Optical Imaging of Preictal Changes in an Animal Model}

Despite the discovery of preictal optical signals in human spontaneous epilepsy, many of our animal studies in pharmacologically induced recurrent focal neocortical seizures using 4-aminopyridine injection did not find any preictal changes in intrinsic optical imaging, autofluorescence flavoprotein metabolism, or direct tissue mea-

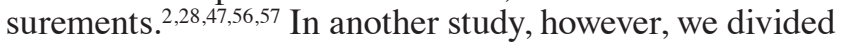
these 4-aminopyridine seizures into two groups based on their electrographic onset pattern. While some seizures began with a large population spike, followed by LVFA, 

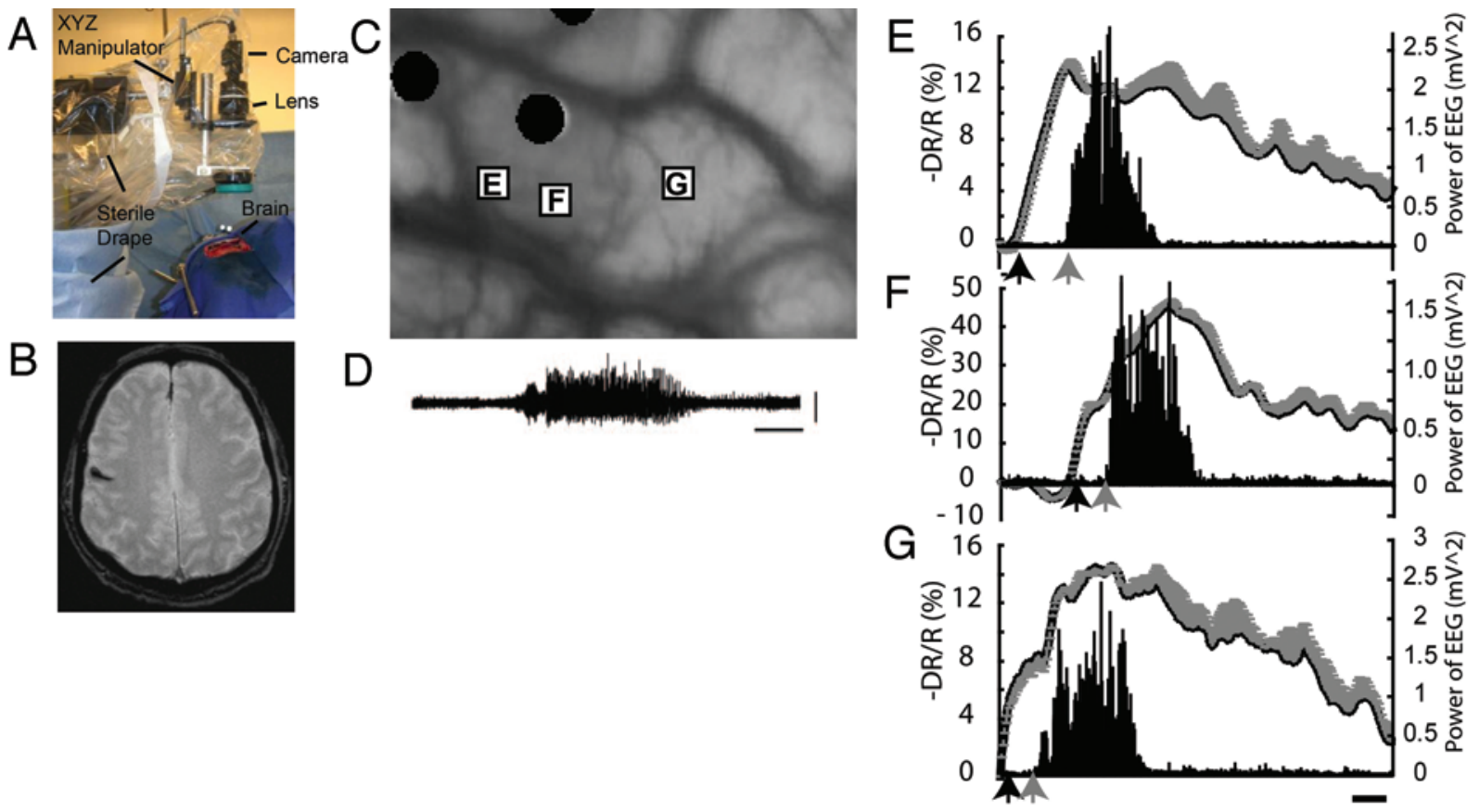

Fig. 1. Preictal changes of optical signal in human epilepsy. A: A custom camera holder with $x-y-z$ gross and fine manipulators suspends a camera, lens, and ring illuminator, draped in sterile plastic, over the exposed human cortex. B: Gradient echo axial MR image demonstrates a small cavernous malformation in the right motor strip. C: Surface of the brain under glass footplate. The black circles highlight the location of the recording electrodes. The lettered boxes demonstrate 3 regions of interest (ROIs) that contained the pixel values with the most statistically significant changes for each of the 3 seizures. The label in each box corresponds to the graphs in E-G. D: An ECoG recording of a typical seizure. Scale bars 20 sec and $1 \mathrm{mV}$. The time course of oximetry ( $E$ and $F$ ) and perfusion-related intrinsic optical signal $(G)$ calculated as $-\Delta R / R(\%)$ during each seizure from each $\mathrm{ROI}$ in $\mathrm{C}$ is graphed along with the power of the ECoG. Error bars represent the SD of pixel values from each ROI. The onset of statistically significant optical signal changes is indicated with a black arrow, and the onset of significant change in the power of the ECoG is indicated with a gray arrow (see detail in reference 18).

others began with LVFA without an initial spike. Of the 67 seizures, 47 began with an initial spike and 20 began without the initial spike. Using ORIS to record CBV, when an initiating spike occurred, increases were identified $0.653 \pm 0.482 \mathrm{sec}$ after the initial spike. However, for the 20 seizures that did not begin with an initial spike but an LVFA recruiting rhythm, CBV increases occurred $1.525 \pm 1.218 \mathrm{sec}$ before the first significant change in the LFP. $^{27}$ Thus, preictal increases in CBV can depend on pattern of seizure onset (Fig. 2).

\section{Surrounding Vasoconstriction of Preictal Signals}

To determine the etiology of the preictal vascular signals, we recently used 2-photon imaging to measure changes in arteriolar diameter during acute 4-aminopyridine-induced seizures and found preictal vasoconstriction in the cortex surrounding an ictal focus. ${ }^{57}$ In vivo images of cortical vasculature were used to measure vessel diameter (Fig. 3A). High-magnification movies of individual arterioles allowed for tracking diameter changes during seizure activity near to (Fig. 3B and C) and far from (Fig. 3D and E) the seizure focus (Fig. 3A-E). We found that arterioles dilated in response to the seizure in the focus, with a decreasing amount of dilation with increasing distance from the 4-aminopyridine injection site ( $n=4$ rats, 71 vessels, 45 seizures, 143 measurements). Plotting the temporal profile of vasodilation compared with vasoconstriction (Fig. $3 \mathrm{~F}$ and $\mathrm{G}$ ), we determined that vasodilation in the focus occurred $0.5 \pm 0.1 \mathrm{sec}$ after seizure onset, whereas vasoconstriction in the surround occurred $5.3 \pm 0.5 \mathrm{sec}$ before seizure onset. Note that all vasoconstriction was observed to occur before seizure onset.

In previous studies, we had demonstrated inverted ORIS in the surround consistent with a decrease in CBV. ${ }^{56}$ It was not clear from these studies whether the surrounding decrease in $\mathrm{CBF}$ or $\mathrm{CBV}$ was caused by a passive shunting of blood into the ictal focus or by active shunting of blood due to vasoconstriction on the surrounding brain tissue. Using the 2-photon microscope to look directly at the arterioles, we demonstrated active preictal vasoconstriction, indicating that ictal onset may be preceded by vasoconstriction in small arterioles surrounding an ictal focus. The etiology of preictal surround vasoconstriction is unclear. One possibility is the active shunting of oxygenated blood to the imminent seizure focus. Another possibility is that the vasoconstriction is a reaction to preictal surround inhibition in the "ictal penumbra." 38,50

\section{Discussion}

Preictal optical imaging studies in both human and animal seizures provides converging evidence for the existence of anticipatory changes in CBF and hemoglobin 

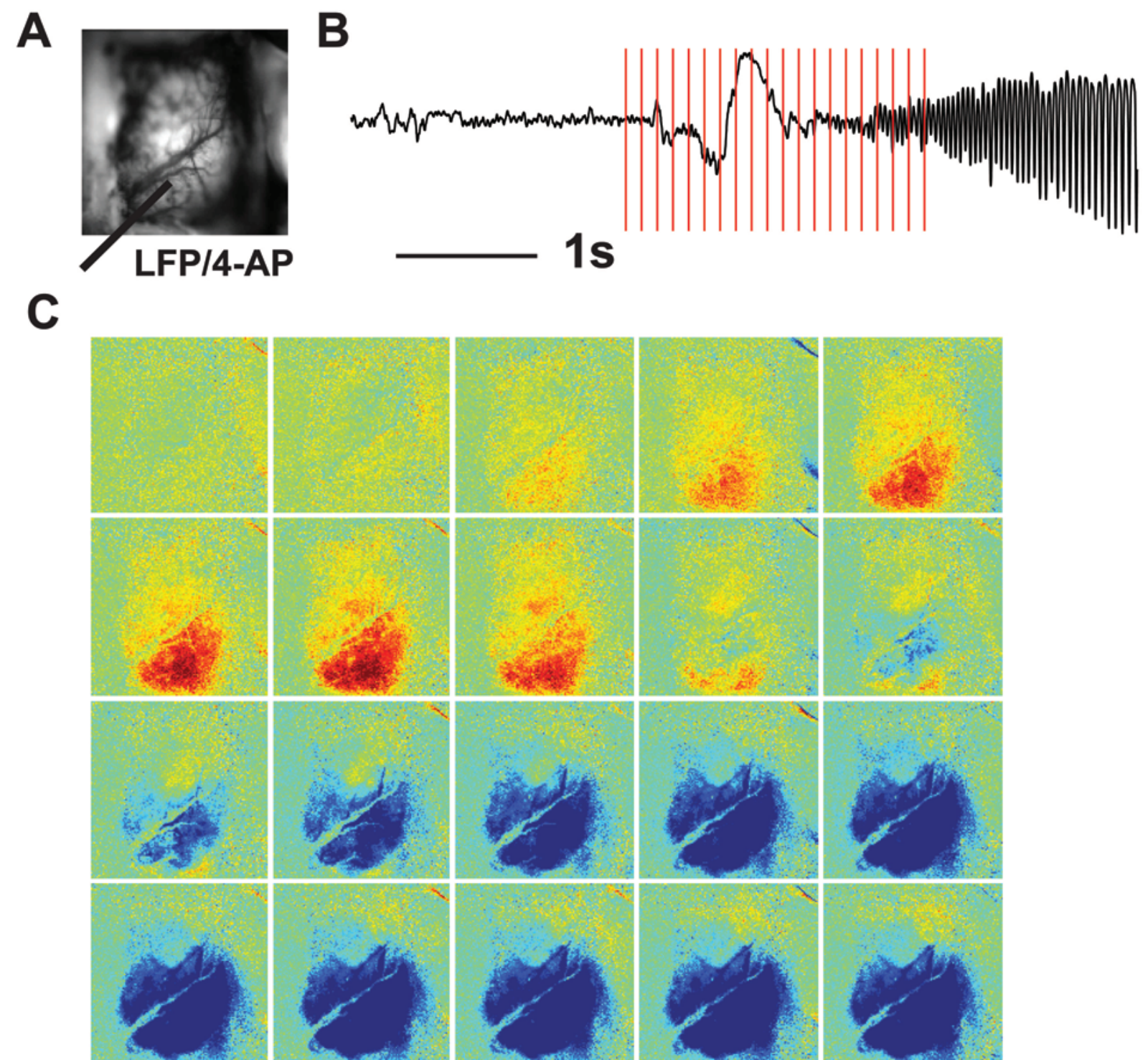

FIG. 2. Preictal decrease in CBV precedes seizure onset. A: Image of cortical surface to demonstrate location of 4-aminopyridine (4-AP) and LFP electrode (gray bar). B: An LFP recording of one seizure. The vertical lines show the frame markers in $C$. The CBV images at selected time points (B) with respect to seizure onset show a preictal decrease in CBV and then an increase in CBV after seizure onset (light indicates the decrease of CBV and the dark indicates the increase of CBV).

oxygenation. Although the etiology of those changes is currently unknown, ORIS can be used as a method to detect these early events. Whether these vascular events are truly preictal or, rather, represent subtle underlying neuronal or glial events is also unclear and will require more sensitive measurements of both signals. For example, fast ripples (very high frequency activity) and microseizures have been recorded in human epilepsy using high-resolution ECoG techniques, , $22,36,37,43,44$ which were not applied in our aforementioned studies. Ictal change in the ECoG or the LFP are a reflection of synchronous dendritic activity in large groups of neurons. In optical imaging, intrinsic signal recordings mostly arise from subthreshold activity in an area 5-10 times larger than the area of spiking cells. Hence, subtle preictal activity may not be recorded by the ECoG or LFP electrode but may be clearly recorded by optical methods. Addition- ally, preictal signals may not be elicited by neurons but, rather, by astrocyte- or pericyte-medicated signaling or local potassium and local neurotransmitter/neuropeptide release. . $^{140,21,32,51}$ Hemodynamic changes may also be influenced by glia, which are not directly recorded with standard electrophysiological methods.

What is the significance of the preictal optical signal? The ultimate goal of optical seizure prediction is not only to warn of an impending seizure but also to prevent seizure from occurring. New novel epilepsy therapies such as cortical stimulation, local short-acting, powerful drug application, and focal cooling have been investigated to stop seizures. . $11,24,31,45$ All of these methodologies would be more efficacious if those closed-loop intervention systems could predict the onset of seizures.

Currently, most of those systems use recording electrodes to provide ongoing feedback of cortical physiology. 


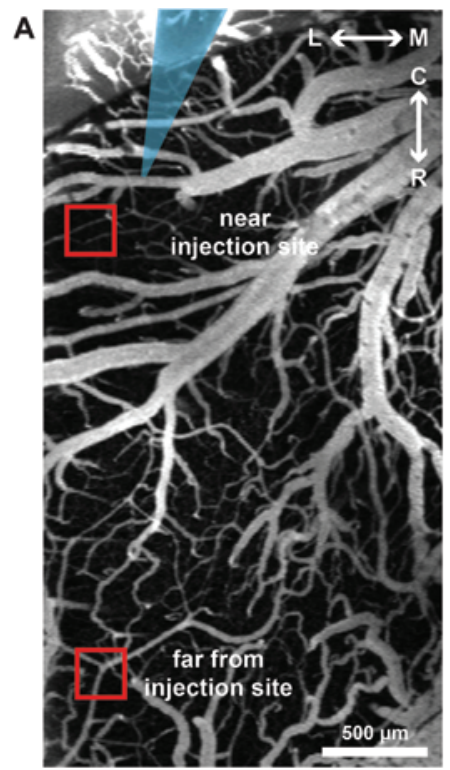

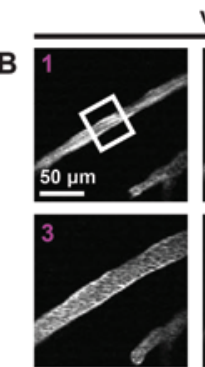

vessel near injection site $(324 \mu \mathrm{m})$
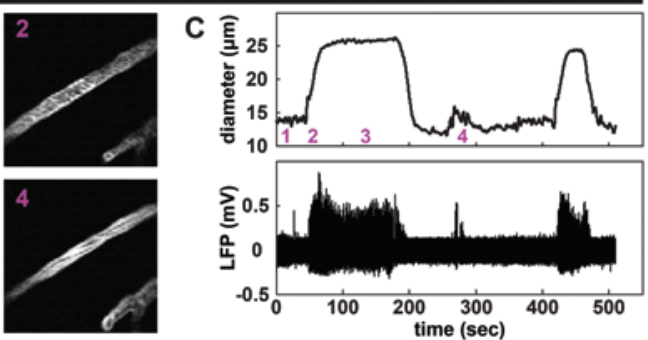

vessel far from injection site $(2160 \mu \mathrm{m})$
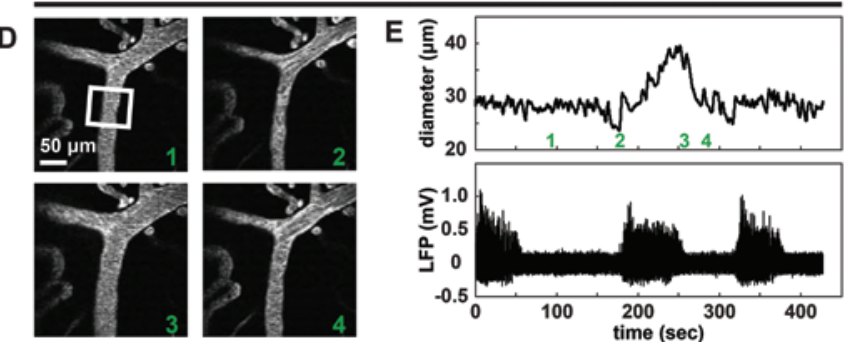
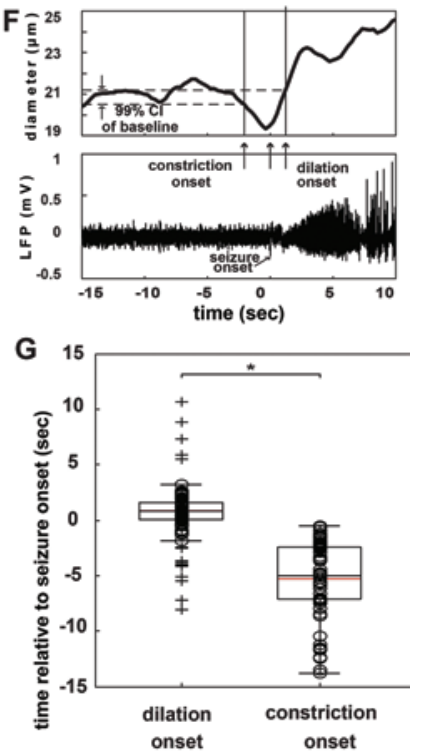

FIG. 3. Seizures induce spatially dependent vascular changes. A: Two-photon image of fluorescence-labeled surface vasculature (blue arrow shows the implanted electrode, and boxed areas, near and far regions from the seizure focus, are highlighted in $B-E)$. $L \leftrightarrow M=$ lateral-medial axis; $C \leftrightarrow R=$ caudal-rostral axis. Scale bar $500 \mu \mathrm{m}$. B: Example of a representative vessel adjacent to the injection site in the focus, demonstrating vascular dilation concurrent with seizure onset and evolution. C: Plot of vessel diameter (upper) in the white box in B during ictal events (lower). Note vascular dilation with each event. Numbered time stamps in C upper correspond to images in B. D: Two-photon images in located vessel greater than $2 \mathrm{~mm}$ from the injection site, revealing a transient constriction of arterioles at the onset of the seizure. E: Plot of vessel diameter (upper) in the white box in D during ictal events (lower). Note vascular constriction at the onset of each event, followed by dilation. Numbered time stamps in E upper correspond to images in D. F: Representative example of vascular diameter (upper) and simultaneous LFP recording (lower) of seizure onset, demonstrating preictal vasoconstriction and postictal vasodilation. A 99\% confidence interval about the mean diameter is shown in F. Arrows, from left to right, indicate constriction (first arrow), seizure onset (second arrow), and dilation (third arrow). G: Boxplot of dilation- and constriction-onset times relative to seizure onset. Gray and black lines represent mean and median, respectively. Circles are individual data points and cross hairs are statistical outliers. ${ }^{*} p<1.0 \mathrm{E}-7$. (n $=4$ rats, 71 vessels, 45 total seizures, 143 total measurements). ${ }^{57}$

The number and location of electrodes may be important to provide a sufficiently early detection of an ongoing seizure. Complex mathematical algorithms applied to electrographic data for seizure prediction have recently garnered much attention. ${ }^{26}$ The preictal optical signals we describe here may provide an alternative method. Additionally, the optical method is a noninvasive measurement that can avoid the brain damage caused by implanted electrodes. ${ }^{9}$ New neuroimaging and neuromodulatory techniques such as "optogenetics," which combines optical and genetic techniques, have emerged as popular tools to probe and control neuronal function with light. ${ }^{1,4,5,54,55}$ Recently, optical suppression of epilepsy has been studied by using optogenetic techniques and caged compounds. ${ }^{49,53}$ The combination of optical preictal detection and optical control would make a novel optical device to terminate seizures.

Preictal optical imaging may also help to identify the ictal focus in patients with nonlesional epilepsy. Nonlesional epilepsy surgery usually has a lower chance of seizure-free outcome than lesional epilepsy surgery. ${ }^{48}$ Precise location of a preictal and ictal onset zone in presurgical planning would result in more effective neurosurgical resections.

\section{Conclusions}

In summary, new novel optical imaging techniques show clear preictal optical signals from both epilepsy in humans and acute pharmacologically induced seizures in animal models. Optical measurements of blood flow and oxygenation may be extremely useful tools for predicting and localizing seizure onset, which can have a myriad of uses in warning patients and triggering abortive therapies. Those methods have great potential to assist the neurosurgeon not only in localizing the seizure onset but also in triggering a closed-loop, real-time, online device to predict and terminate seizures.

\section{Disclosure}

This work was supported by an NINDS Grant No. RO1 NS49482 (T.H.S.), CURE Taking Flight Award (H.M.), Clinical and Translational Science Center (Grant No. UL1 RR 024996) Pilot Grant (M.Z.), and the Cornell University Ithaca-WCMC seed grant (M.Z.).

The authors report no conflict of interest concerning the materials or methods used in this study or the findings specified in this paper.

Author contributions to the study and manuscript preparation include the following. Conception and design: Schwartz, Zhao. Acquisition of data: all authors. Analysis and interpretation of data: all authors. Drafting the article: all authors. Critically revising the article: all authors. Reviewed submitted version of manuscript: all authors. Approved the final version of the manuscript on behalf of all authors: Schwartz. Statistical analysis: Zhao, Ma. Administrative/ technical/material support: Schwartz. Study supervision: Schwartz. 


\section{References}

1. Adamantidis AR, Zhang F, Aravanis AM, Deisseroth K, de Lecea L: Neural substrates of awakening probed with optogenetic control of hypocretin neurons. Nature 450:420-424, 2007

2. Bahar S, Suh M, Zhao M, Schwartz TH: Intrinsic optical signal imaging of neocortical seizures: the 'epileptic dip.' Neuroreport 17:499-503, 2006

3. Bhatia S, Ragheb J, Johnson M, Oh S, Sandberg DI, Lin WC: The role of optical spectroscopy in epilepsy surgery in children. Neurosurg Focus 25(3):E24, 2008

4. Boison D: Adenosine and epilepsy: from therapeutic rationale to new therapeutic strategies. Neuroscientist 11:25-36, 2005

5. Boison D: Adenosine kinase, epilepsy and stroke: mechanisms and therapies. Trends Pharmacol Sci 27:652-658, 2006

6. Bragin A, Mody I, Wilson CL, Engel J Jr: Local generation of fast ripples in epileptic brain. J Neurosci 22:2012-2021, 2002

7. Burton JM, Peebles GA, Binder DK, Rothman SM, Smyth MD: Transcortical cooling inhibits hippocampal-kindled seizures in the rat. Epilepsia 46:1881-1887, 2005

8. Chaudhary UJ, Duncan JS, Lemieux L: Mapping hemodynamic correlates of seizures using fMRI: a review. Hum Brain Mapp 34:447-466, 2013

9. Cox MP, Ma H, Bahlke ME, Beck JH, Schwartz TH, Kymissis I: LED-based optical device for chronic in vivo cerebral blood volume measurement. IEEE Trans Electron Dev 57:174-177, 2010

10. Diehl B, Knecht S, Deppe M, Young C, Stodieck SR: Cerebral hemodynamic response to generalized spike-wave discharges. Epilepsia 39:1284-1289, 1998

11. Eder HG, Stein A, Fisher RS: Interictal and ictal activity in the rat cobalt/pilocarpine model of epilepsy decreased by local perfusion of diazepam. Epilepsy Res 29:17-24, 1997

12. Federico P, Abbott DF, Briellmann RS, Harvey AS, Jackson GD: Functional MRI of the pre-ictal state. Brain 128:18111817,2005

13. Feldwisch-Drentrup H, Staniek M, Schulze-Bonhage A, Timmer J, Dickten H, Elger CE, et al: Identification of preseizure states in epilepsy: a data-driven approach for multichannel EEG recordings. Front Comput Neurosci 5:32, 2011

14. Filosa JA, Bonev AD, Straub SV, Meredith AL, Wilkerson MK, Aldrich RW, et al: Local potassium signaling couples neuronal activity to vasodilation in the brain. Nat Neurosci 9:1397-1403, 2006

15. Frostig RD, Lieke EE, Ts'o DY, Grinvald A: Cortical functional architecture and local coupling between neuronal activity and the microcirculation revealed by in vivo high-resolution optical imaging of intrinsic signals. Proc Natl Acad Sci U S A 87:6082-6086, 1990

16. Gavaret M, McGonigal A, Badier JM, Chauvel P: Physiology of frontal lobe seizures: pre-ictal, ictal and inter-ictal relationships. Suppl Clin Neurophysiol 57:400-407, 2004

17. Gibbs FA: Cerebral blood flow preceding and accompanying experimental convulsions. Arch Neurol Psychiatry 30:10031010,1933

18. Haglund MM: Optical imaging of visual cortex epileptic foci and propagation pathways. Epilepsia 53 (Suppl 1):87-97, 2012

19. Haglund MM, Ojemann GA, Hochman DW: Optical imaging of epileptiform and functional activity in human cerebral cortex. Nature 358:668-671, 1992

20. Hamel E: Perivascular nerves and the regulation of cerebrovascular tone. J Appl Physiol 100:1059-1064, 2006

21. Hamel E, Day BW, Miller JH, Jung MK, Northcote PT, Ghosh AK, et al: Synergistic effects of peloruside A and laulimalide with taxoid site drugs, but not with each other, on tubulin assembly. Mol Pharmacol 70:1555-1564, 2006

22. Jiruska P, Finnerty GT, Powell AD, Lofti N, Cmejla R, Jefferys
JGR: Epileptic high-frequency network activity in a model of non-lesional temporal lobe epilepsy. Brain 133:1380-1390, 2010

23. Katz A, Marks DA, McCarthy G, Spencer SS: Does interictal spiking change prior to seizures? Electroencephalogr Clin Neurophysiol 79:153-156, 1991

24. Kossoff EH, Ritzl EK, Politsky JM, Murro AM, Smith JR, Duckrow RB, et al: Effect of an external responsive neurostimulator on seizures and electrographic discharges during subdural electrode monitoring. Epilepsia 45:1560-1567, 2004

25. Ledri M, Nikitidou L, Erdelyi F, Szabo G, Kirik D, Deisseroth $\mathrm{K}$, et al: Altered profile of basket cell afferent synapses in hyper-excitable dentate gyrus revealed by optogenetic and twopathway stimulations. Eur J Neurosci 36:1971-1983, 2012

26. Litt B, Echauz J: Prediction of epileptic seizures. Lancet Neurol 1:22-30, 2002

27. Ma H, Zhao M, Schwartz TH: Dynamic neurovascular coupling and uncoupling during ictal onset, propagation, and termination revealed by simultaneous in vivo optical imaging of neural activity and local blood volume. Cereb Cortex [epub ahead of print], 2012

28. Ma H, Zhao M, Suh M, Schwartz TH: Hemodynamic surrogates for excitatory membrane potential change during interictal epileptiform events in rat neocortex. J Neurophysiol 101:2550-2562, 2009

29. Malonek D, Grinvald A: Interactions between electrical activity and cortical microcirculation revealed by imaging spectroscopy: implications for functional brain mapping. Science 272:551-554, 1996

30. Mormann F, Andrzejak RG, Elger CE, Lehnertz K: Seizure prediction: the long and winding road. Brain 130:314-333, 2007

31. Motamedi GK, Salazar P, Smith EL, Lesser RP, Webber WRS, Ortinski PI, et al: Termination of epileptiform activity by cooling in rat hippocampal slice epilepsy models. Epilepsy Res 70:200-210, 2006

32. Peppiatt CM, Howarth C, Mobbs P, Attwell D: Bidirectional control of CNS capillary diameter by pericytes. Nature 443: 700-704, 2006

33. Prakash N, Uhlemann F, Sheth SA, Bookheimer S, Martin N, Toga AW: Current trends in intraoperative optical imaging for functional brain mapping and delineation of lesions of language cortex. Neuroimage 47 (Suppl 2):T116-T126, 2009

34. Rogowski Z, Gath I, Bental E: On the prediction of epileptic seizures. Biol Cybern 42:9-15, 1981

35. Sato K, Nariai T, Sasaki S, Yazawa I, Mochida H, Miyakawa $\mathrm{N}$, et al: Intraoperative intrinsic optical imaging of neuronal activity from subdivisions of the human primary somatosensory cortex. Cereb Cortex 12:269-280, 2002

36. Schevon CA, Goodman RR, McKhann GJ Jr, Emerson RG: Propagation of epileptiform activity on a submillimeter scale. J Clin Neurophysiol 27:406-411, 2010

37. Schevon CA, Ng SK, Cappell J, Goodman RR, McKhann GJ Jr, Waziri A, et al: Microphysiology of epileptiform activity in human neocortex. J Clin Neurophysiol 25:321-330, 2008

38. Schevon CA, Weiss SA, McKhann G Jr, Goodman RR, Yuste $\mathrm{R}$, Emerson RG, et al: Evidence of an inhibitory restraint of seizure activity in humans. Nat Commun 3:1060, 2012

39. Schwartz TH, Chen LM, Friedman RM, Spencer DD, Roe AW: Intraoperative optical imaging of human face cortical topography: a case study. Neuroreport 15:1527-1531, 2004

40. Schwartz TH, Hong SB, Bagshaw AP, Chauvel P, Bénar CG: Preictal changes in cerebral haemodynamics: review of findings and insights from intracerebral EEG. Epilepsy Res 97: 252-266, 2011

41. Sheth SA, Nemoto M, Guiou M, Walker M, Pouratian N, Hageman N, et al: Columnar specificity of microvascular oxygenation and volume responses: implications for functional brain mapping. J Neurosci 24:634-641, 2004 


\section{Intrinsic optical imaging of seizure onset}

42. So EL, O'Brien TJ: Peri-ictal single-photon emission computed tomography: principles and applications in epilepsy evaluation, in Hermann S, William HT (eds): Handbook of Clinical Neurology. Edinburgh: Elsevier, Vol 107, 2012, pp 425-436

43. Staba RJ, Frighetto L, Behnke EJ, Mathern GW, Fields T, Bragin A, et al: Increased fast ripple to ripple ratios correlate with reduced hippocampal volumes and neuron loss in temporal lobe epilepsy patients. Epilepsia 48:2130-2138, 2007

44. Stead M, Bower M, Brinkmann BH, Lee K, Marsh WR, Meyer FB, et al: Microseizures and the spatiotemporal scales of human partial epilepsy. Brain 133:2789-2797, 2010

45. Stein AG, Eder HG, Blum DE, Drachev A, Fisher RS: An automated drug delivery system for focal epilepsy. Epilepsy Res 39:103-114, 2000

46. Suh M, Bahar S, Mehta AD, Schwartz TH: Blood volume and hemoglobin oxygenation response following electrical stimulation of human cortex. Neuroimage 31:66-75, 2006

47. Suh M, Ma H, Zhao M, Sharif S, Schwartz TH: Neurovascular coupling and oximetry during epileptic events. Mol Neurobiol 33:181-197, 2006

48. Téllez-Zenteno JF, Hernández Ronquillo L, Moien-Afshari F, Wiebe S: Surgical outcomes in lesional and non-lesional epilepsy: a systematic review and meta-analysis. Epilepsy Res 89:310-318, 2010

49. Tønnesen J, Sørensen AT, Deisseroth K, Lundberg C, Kokaia M: Optogenetic control of epileptiform activity. Proc Natl Acad Sci U S A 106:12162-12167, 2009

50. Trevelyan AJ, Schevon CA: How inhibition influences seizure propagation. Neuropharmacology [epub ahead of print], 2012

51. Wang X, Lou N, Xu Q, Tian GF, Peng WG, Han X, et al: Astrocytic $\mathrm{Ca} 2+$ signaling evoked by sensory stimulation in vivo. Nat Neurosci 9:816-823, 2006
52. Williamson JR, Bliss DW, Browne DW, Narayanan JT: Seizure prediction using EEG spatiotemporal correlation structure. Epilepsy Behav 25:230-238, 2012

53. Yang XF, Schmidt BF, Rode DL, Rothman SM: Optical suppression of experimental seizures in rat brain slices. Epilepsia 51:127-135, 2010

54. Zayat L, Noval MG, Campi J, Calero CI, Calvo DJ, Etchenique R: A new inorganic photolabile protecting group for highly efficient visible light GABA uncaging. ChemBioChem 8: 2035-2038, 2007

55. Zhang F, Wang LP, Brauner M, Liewald JF, Kay K, Watzke N, et al: Multimodal fast optical interrogation of neural circuitry. Nature 446:633-639, 2007

56. Zhao M, Ma H, Suh M, Schwartz TH: Spatiotemporal dynamics of perfusion and oximetry during ictal discharges in the rat neocortex. J Neurosci 29:2814-2823, 2009

57. Zhao M, Nguyen J, Ma H, Nishimura N, Schaffer CB, Schwartz TH: Preictal and ictal neurovascular and metabolic coupling surrounding a seizure focus. J Neurosci 31:13292-13300, 2011

58. Zhao M, Suh M, Ma H, Perry C, Geneslaw A, Schwartz TH: Focal increases in perfusion and decreases in hemoglobin oxygenation precede seizure onset in spontaneous human epilepsy. Epilepsia 48:2059-2067, 2007

Manuscript submitted December 14, 2012.

Accepted January 25, 2013.

Please include this information when citing this paper: DOI: 10.3171/2013.1.FOCUS12408

Address correspondence to: Theodore H. Schwartz, M.D., Department of Neurological Surgery, Weill Medical College of Cornell University, 525 East 68th Street, Box 99, New York, New York 10065.email: schwarh@med.cornell.edu. 